\title{
Development of 3D learning objects for orthopedics, with the support of the Scrum framework
}

\author{
Maicon Herverton Lino Ferreira da Silva \\ Faculty Officer Osman da Costa Lins (FACOL) \\ Brazil \\ maicon.lino@dr.com
}

\author{
Marcelo Mendonça Teixeira \\ Faculty Officer Osman da Costa Lins (FACOL) \\ Brazil \\ marcelo.ufrpe.br@gmail.com
}

\author{
Augusto José da Silva Rodrigues \\ Federal University of Campina Grande (UFCG) \\ Brazil \\ augustojsrodrigues@gmail.com \\ Robson Fernandes Barbosa \\ Federal University of Campina Grande (UFCG) \\ Brazil \\ robson_rfb@yahoo.com.br
}

\begin{abstract}
The Stewart Platforms (SP) bring relevant contributions to handling $3 D$ environments. Among these contributions, the Ilizarov Hexapod Systems (IHS) are developed, aimed at correcting bone deformities. Thus, with the support of the Scrum framework, the development of a set of four $3 D$ learning objects (3DLOs) was carried out, and was then evaluated by eight orthopedic doctors and eleven orthopedic residents. Finally, the contributions of the use of the software engineering Scrum framework in the construction of 3DLOs and its effectiveness as an instructional mechanism in IHS teaching-learning medicine were presented.
\end{abstract}

Index Terms- Stewart Platforms, Ilizarov Hexapod System, Scrum, 3D Learning Objects.

\section{INTRODUCTION}

The new sociability behaviors promoted new ways of technological development, changing, shifting and creating unusual relations between Man and information and communication technologies [1]. This was exactly what happened at the turn of the 20th century to 21 st century when many revolutionary network communication electronic devices were developed. To Teixeira [42], as a consequence of globalization and technological growth, the subsequent multiculturalism established a new social structure, consisting of different kinds of people and corporations. Research and development have been carried out through a reflective analysis of nature's behavior, seeking to learn from its strategies and solutions. Systems that copy the movements or the behaviors of nature are called biomimicry (biomimetics). On the other hand, systems that are inspired by nature but that create new types of mechanisms are called bio-inspirations [35]. Systems using bio-inspirations or biomimicry have many applications. A well-known example is the system called Velcro that was developed through the observation of grass seeds which had spines and hooks to get attached to dogs' hair [12]. Another example of bioinspiration was recently presented by Chouw et al. [5] who designed a robot bioinspired in another hexapod's moments (the cockroach) to climb the stairs.

In the $1960 \mathrm{~s}$, starting from the idea of copying the movements of nature, D. Stewart introduced a parallel handler with six identical legs that allowed movements in six degrees of freedom [29]. This handler, once used as a hydraulic actuator mechanism for robots that performed translational movements, is now used as a flight simulator for pilot training. As soon as it became popular, it became known as Stewart Platform (SP) [34]. The use of SP as flight simulators expanded. Later, they were also used to build the first simulators based on a hexapod's architecture [17], let's see:

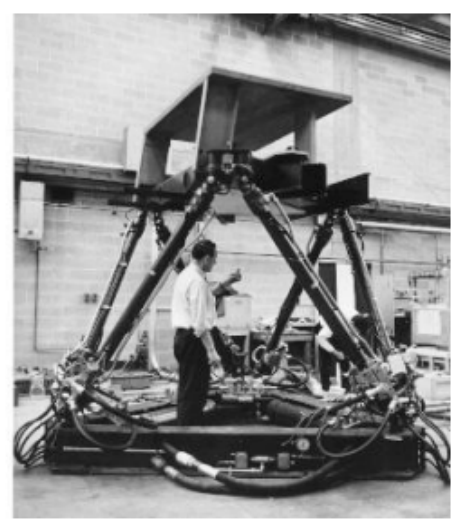

Fig. 1. First simulator model that built with hexapod's architecture. Source: $[18$, p. 11].

Due to technological advancement, business leaders that worked with flight simulators were able to start the production of robust and modern simulators with electric cylinders instead of the original hydraulic cylinders platforms. This change brought a cost reduction on the production of simulators, as well as a greater precision on their movements [41].

As the use of SP was expanded, an interest in the use and adaptation of its methodology to a variety of issues arose. An example of this is the change made to the Ilizarov external fixator (IEF) [10], portrayed in Figure 2. The IEF was originally designed to elongate body members, however, by using SP's principles, it also started to be applied on the improvement of the quality of life of patients with congenital anomalies and people who have suffered accidents. The new system was able to correct musculoskeletal systems that presented bone deformities:

This new system based on the IEF is called Ilizarov hexapod system (IHS). This system embraced SP mechanisms and brought a new method for remediation of bone malformation to orthopedics, allowing doctors to 
perform movements with six degrees of freedom to correct bones' deformities.

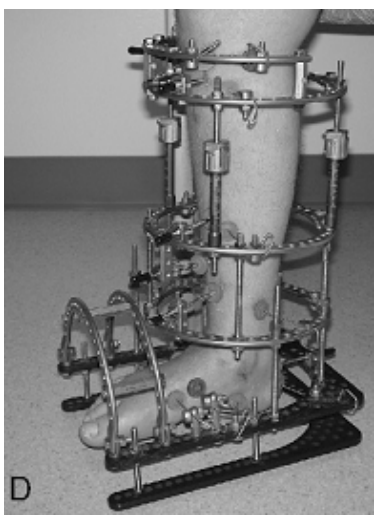

Fig. 2. An Ilizarov external fixator implanted on a patient's leg. Source: [10, p. 161].

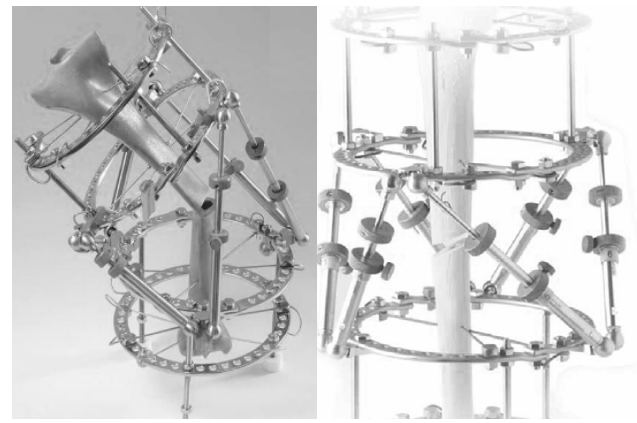

Fig. 3. Ilizarov hexapod system mounted on a bone deformity, and after correction of the deformity Source: [10, p. 161].

A. Congenital malformations and deformities caused by accidents

The problems of congenital malformations are changes throughout the growth and development of some human beings that corroborates with every change in the structural, functional or metabolic order, resulting in physical or mental anomalies. Nevertheless, the term anomaly and malformation are treated as synonymous and used to describe all types of structural changes [26].

Worldwide, these anomalies already affected about 5\% of children born alive [22] in the mid-1990s. Reis, Santos and Mendes [39] demonstrate that this reality remains the same. In Brazil, congenital malformations have represented one of the major causes of infant mortality, causing approximately $11.2 \%$ of deaths in this category [26].

According to Ramos, Oliveira and Cardoso [26] the genetics is a major cause of birth defects, corresponding to somewhere around 25-50 percent of the cases. Environmental, infectious factors, radiation or administration of drugs represent around 3 percent of the cases. Unknown causes represent 43-69 percent of the cases.

Early identification of a congenital syndrome can significantly increase possibilities of treatment. Therefore, it is imperative that doctors are able to identify patients' characteristics that may be correlated with birth defects, so that the patient can be referred to a geneticist.

Congenital syndromes' identification requires specialized knowledge. One needs to be interested in genetics and seek medical qualifications that will enable the identification of congenital deformities. Some birth defects, however, are easily identifiable, especially those affecting the musculoskeletal system.

The problems that affect the musculoskeletal system represent, according to Ramos, Oliveira and Cardoso [26], about 30 percent of cases of malformation. According to those authors, in the International Classification of Diseases (ICD) 10 percent of cases of malformation had more than one type of congenital malformation and, among these, 58.3 percent presented polydactyly and 16.7 percent presented both foot and chest deformity. This shows that the problems that affect the musculoskeletal system are present in dysmorphology and that they need treatment and accompaniment by a specialized geneticist.

The term 'dysmorphology' emerged in the 1960s to replace the term 'teratology'. Dysmorphology is a field of medical genetics that studies human congenital malformations, which literally means the study of the abnormal form, and focuses structural developmental abnormalities. Due to the fact that doctors do not like being called teratology, dysmorphology is the term most commonly used [16].

Dysmorphology studies focus on malformations that often affect the patients' physical development. Thus, it can focus on malformation of the musculoskeletal system such as the generation of small or crooked bones. It can also focus on the existence of additional bones as in the case of polydactyly, which is a malformation characterized by the presence of more than five fingers on the hands or feet.

Within dysmorphology studies, as previously mentioned, there is a field that focuses on anomalies of the musculoskeletal system malformation. Besides, problems with bone formation also comprise a problem of congenital malformation and they are identified in many patients who have what is popularly called as "crooked bone" in members such as the nose, arm, jaw, leg and also the leg.

As an example, Figure 4 illustrates a 3D side view of leg with and without abnormality, namely, with and without a problem of malformation of the musculoskeletal system.

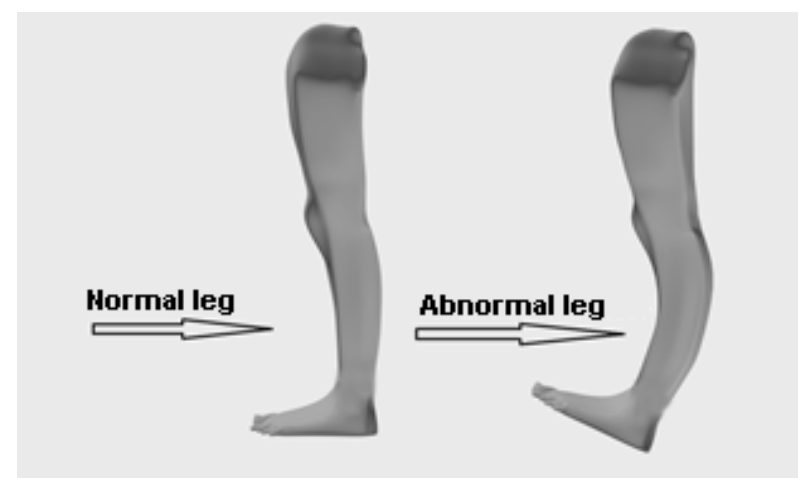

Fig. 4. Leg side view 3D with and without abnormality.

However, this is not the only problem. Serious accidents also generate anomalies in the musculoskeletal system through fractures that often require specialized medical staff to perform the procedures to correct the deformity and to manipulate apparatus such as the Ilizarov hexapod system (IHS). To have such specialized and multidisciplinary knowledge about the appropriate correction process, one must learn about IHS's mathematical structures and functioning. This brings light to the opportunity of using 3D tools, which are more intuitive, to the learning process.

\section{A. Medical education}

Several areas of knowledge have been building methodologies to aid in the teaching and learning processes. Methods for teaching and learning medical knowledge have also been tested and accepted within the medical field [25]. 
Although many ways of knowledge transmission are known, there are still areas that need to be explored in order to seek improvements for the learning process. Even though there are already many teaching methods tested and accepted within the medical field [25], specifically in orthopedics, professors who attempt to lecture in a three-dimensional space (3D) about the correction of bone malformation with HIS still face immense difficulties. This reality was confirmed by the main stakeholder of this project, Doctor Epitácio Rolim Filho, who is an active doctor in the area of IHS and the principal disseminator of knowledge about IHS in Pernambuco, a state located in Northeastern Brazil.

As a result, physicians need further training to learn how to handle IHS within a context in which specialized knowledge regarding movements in three dimensions is required.

Learning objects were created to fill this gap on didactical tools, especially with respect to tools that require a three-dimensional view. According to Wiley [36], learning objects (LOs) are technologies used to increase the learning potential and that are available for reusability, generation, adaptability and scalability. In addition, the LOs are elements of a new way of teaching, based on the object-oriented paradigm of computer science that emphasizes the creation of components which can be reused in various contexts.

Moreover, according to Moran, Masetto and Behrens [19], more knowledge can be processed through multimedia forms, i.e., joining pieces of texts from various overlapping languages that comprise an impressionistic mosaic, which is connected with other multimedia screens. Through this multimedia process, the reading process becomes increasingly less sequential and the construction of knowledge becomes more "free".

Furthermore, multimedia learning contributes to the increasing use of multimedia learning objects (MLOs) as teaching tools for the construction of knowledge. Therefore, it may assist the learning process within medical education, particularly in teaching IHS.

However, there are currently no standards or best practices on the creation of structured or documented MLOs. What usually happens is that a demand is identified; then, a prototype is made and, if approved, utilized. This study used the Scrum framework of software engineering to monitor the process of development of MLOs in order to make them precise and objective for the needs of instructors, agencies, companies or clients.

\section{B. Computer graphics}

Computer graphics is a field of computer science that aims at generating images and models that represents the recreation of a real situation or context. It is widely used to generate animations and virtual games. It emerged in the mid-1960s, and it made possible that advances occurred in different fields of knowledge.

With technological advancement, various techniques to design models in computer graphics have been developed, such as: modeling from images and manual modeling through layers and specifically through techniques that allow the representation of real situations in $3 \mathrm{D}$ modeling or in virtual reality.

According to Silva [31, p. 123] "virtual reality emerged as a leisure option, in which the possibility that the user could participate in a world different than his own became attractive." This becomes possible through computer graphics and the creation of 3D virtual worlds and objects of learning. From this starting point, many fields of study, such as education, medicine, physics, chemistry and architecture, among others, began to use computer graphics as a tool.

An example of the use of computer graphics in large academic areas is the design of plants in engineering. Engineers use tools such as Autocad to model and demonstrate the likely outcome of their work even its architectural aesthetic to clients.

Within the medical field, it is possible to use graphics, computer images, to generate three-dimensional meshes from medical images, and to create LOs that can be used for training programs, for example.

In view of Dev [9], a major goal of medical education is to teach detection (diagnosis) and problem solving, based on extensive knowledge, experiences, and individual analysis of patients. It is also worth noting that the images are an essential element of the learning process.

The learning process lacks technological resources that will enhance the uptake, learning and memorization through sounds and pictures. In this sense, the LOs present a particularity, especially through the $3 \mathrm{D}$ learning objects, as they allow the visual transmission of knowledge. Thus, it is possible to guide knowledge transmission using both visual demonstrations and professor's explanations regarding the images displayed.

Finally, it is noteworthy that this study was initially requested by a doctor at the Association for Assisting Disabled Children (AADC), who identified the need to work in the education of AADC's interns regarding the HIS. Given the difficulties faced when teaching something three dimensional without proper tooling, this doctor saw the need for creating 3D learning objects as part of the interns' learning. He chose to use methods of software engineering to develop the proposed objects.

\section{LEARNING OBJECTS AND KNOWLEDGE BUILDING}

New ways for knowledge to be understood and captured were increasingly gaining amplitude, integrating, connecting and relating with learning and reasoning due to the growth of technology. This reinforces the idea that the informational process happens in various ways and in different cultural universes [19].

One of the most usual ways in which the learning process occurs is the logical-sequential processing. This approach to learning is expressed through the spoken and written language. Within this process, the construction of meaning occurs slowly, sequentially, and within a defined encoding - i.e. language [19].

However, as the recently cited authors complement, currently, the information sent to students is increasingly processed through multimedia formats. In the process, pieces of texts from several overlapping languages are joined and the reading process becomes less sequential.

In this context, the LOs emerge which, according to Wiley [36], would be chosen at that time to the next due generation instructional design, used for the development of learning according to its potential for reusability, generation, adaptability and scalability. In addition, the LOs were elements of a new way of teaching based on the objectoriented paradigm of computer science which values the creation of components that can be reused in various contexts [4]. 
From this perspective, LOs bring significant contributions to the learning process, mainly because they are an interactive web based tool that expands the possibilities for teaching knowledge dissemination. Moreover, learning objects are usually available on the Internet, which makes them accessible for more people, unlike the traditional objects - such as video tapes, projectors or even books - that are only accessible in one place and at a certain time [40].

Also according to Wiley [36], the term "learning objects" came from the Learning Technology Standards Committee (LTSC) to describe small instructional components; this term was also used by Wayne in 1994 as a title in a workgroup. Still according to studies presented by Wiley [36, p. 17] on learning objects, their main features are:

- Number of combined elements: describes the number of individual elements (such as video clips, images etc.) that are combined to form the learning object;

- Type of contained objects: describes the types of learning objects that can be combined to form a new learning object;

- Components of reusable objects: describes if the objects that constitute the learning object may or may not be individually accessed and reused in new learning contexts;

- Common Function: describes the way in which the type of learning objects is generally used;

- Dependence of extra object: describes the learning object requires information (such as network location) about other learning objects;

- Type of logic contained in the object: describes the common function of algorithms and procedures within the learning object;

- Potential for inter-contextual reuse : describes the number of different learning contexts in which the learning object could be used, i.e. the potential of the object to be reused in different content areas or domains;

- Potential for intra- contextual reuse: describes the number of times the learning object could be reused within the same content area or domain.

Using this approach, coupled with computer graphics, one can obtain the 3D multimedia learning objects (3DMLOs), or multimedia learning objects (MLOs), which are graphical tools combined and used to enhance the learning process and the exchange of knowledge between teachers and students, or between professionals.

\section{A. Multimedia Learning Objects}

The use of multimedia resources are being increasingly used for knowledge building and academic purposes with the intention of facilitating, diversifying and contextualizing the construction of knowledge; it is contributing successfully to instructional use in projects [7].

According to Moran, Masetto and Behrens [19] and Conceição et al. [8], the construction of this knowledge from a multimedia processing is "freer", less rigid and sequential, and has a greater sensory appeal, especially the visual appeal. Thus, the use of LOs becomes relevant when it is necessary to give immediate responses and to quickly adapt to a context [20]. Thus the multimedia objects are best used for information processing.

Regarding the use of technology in the classroom, Conceição et al. [8] states that learning with technology means to use technological tools to support the reflective processes as well as the construction of knowledge (cognitive tools). In this case, the key determinant is not technology itself, but the manner in which technology is used, mostly as a cognitive learning strategy. This often provides means for the reuse of intelligent LOs that, through the use artificial intelligence, can contribute to the use of this strategy [30].

As it can be seen, there is a significant interaction between students and the speakers using MLOs since there is a greater sensory appeal when multimedia objects are used. Therefore, the 2DMLOs can be also used as an extension of MLOs and allow best visual and sensory interpretation of the studied object [23].

The objects used for knowledge-building become a powerful tool for teaching, even though hypertext and logical-sequential forms are still necessary; probably, as claimed by Moran, Masetto and Behrens [19], it is possible to obtain a greater impact if start dealing with information primarily through multimedia and this is possible because of the internet, which makes available a large number of MLOs that can be reused in different contexts [28].

However, the use of learning objects is essential in some fields of education, and many of these fields have large repositories of objects which are evaluated by their own communities of users [38]. This is the case of medicine. Some medical procedures require the knowledge on multidisciplinary areas, explanation in three dimensions, advanced knowledge of robotics, and graphical views in order to allow a doctor to understand a specific problem or situation.

In this sense, the LOs applied to health emerge due to the need to get quick responses for the knowledge construction process. These fast answers are needed both to generate an a priori understanding of a problem and to build a more generic approach to the knowledge.

\section{B. Learning Objects in Health}

The advancement in medical knowledge was accompanied and even promoted by technological advancements and many teaching tools for medical education were developed, such as the 3DMLOs. In Brazil, one of the greatest examples of this is the Virtual Human Project or "Projeto Homem Virtual" [24], led by the University of São Paulo.

Internationally, many repositories for the storage of LOs have emerged [13]. One of the main and most internationally known repositories is the Multimedia Educational Resource for Learning and Online Teaching (MERLOT), which according Nangia [21], is a growing collection of teachinglearning online materials, which is peer reviewed, serves many disciplines, and has been developed by an international consortium of agencies and institutions.

According to Cochrane [6], this is an easy method to find objects of various natures. He also mentions that "repositories usually consist of searchable online databases and often also include assessments of learning objects. A collection of useful links to find learning object is hosted by the University of Alberta (Academic Advanced Distributed Learning Co-Lab). The website also provides a brief description and overview of each repository, giving a good comparison of each. “

In Brazil, for example, there is the International Database of Educational Objects [3], which has educational materials accessible to the public in various formats and for all levels of education. During the realization of this work, there were near twenty thousand objects published, near five and a half 
million visitors from 185 countries, and about a hundred objects in health professional education in the collection.

The Virtual Human Project is among the Brazilian projects that created learning objects within the medical field. This project involves the development of threedimensional images of body structures using computer graphics capabilities, with dynamic images that reproduce the components of the human body - from molecules to muscles - presenting scientific knowledge in an objective, simple and fast way. This project makes possible to understand not only the human anatomy and physiology, but also to see demonstration of pathologies, drug stocks and techniques for surgical procedures.

Other projects also contribute to the construction of learning objects for health [37], such as the project created by Ribeiro [27] to identify dysmorphologies by using 3DMLOs. Other projects seek the reuse of existing LOs [37] in order to reduce the cost to produce a 3DMLOs. The costs associated with a $3 \mathrm{DMLO}$ in this case are lower than if one was to create it from scratch using generic tools to build 3D objects, do video editing, etc. [2].

The health problem analyzed in this work originated from the fact that it was hard to explain something about the functioning of the IHS using only 2D tools. The coordinator of the orthopedic team AADC partnered with UFRPE to develop a set of 3DMLOs that could be used to teach AADC's interns or to advice and inform patients who receive treatment with this type of tool.

\section{EVALUATION}

This research project was conducted in accordance with the requests of the doctor in charge of this project, using four 3DMLOs developed by Silva [32] and following the Scrum method of software engineering that was adapted by the author. It met the need to evaluate if there was a significant increase in the level of understanding of orthopedic interns and orthopedic specialists regarding the HIS technologies with and without the use of 3DMLOs.

The evaluation process was conducted with doctors who were divided into two distinct groups:

- Group one - formed by orthopedic interns (interns)

- Group two - formed by doctors specializing in orthopedic external fixators (experts).

A brief explanation of Ilizarov hexapods systems was presented and then the doctor responsible for the project, Epitácio Rolim Filho, gave assessment forms to orthopedics interns (Group one) in order to assess their level of knowledge about the four 3DMLOs. After an attending physician introduced the four 3DMLOs developed, the form was applied again in order to assess interns' level of knowledge of the four 3DMLOs. At this point, the experts (Group two) also participated and evaluated the 3DMLO, using the same type of form.

The questions of the form requested that respondents positioned themselves about their level of knowledge by using a scale. The scale was represented by a straight line that contained the indications "No Understanding" and "Deep Understanding" in each of its extremes [14].

According to Ribeiro [27], it is possible to assign a numerical value to the qualitative response marked on the line, enabling the measurement of quality. To achieve this purpose, a segment that was 14 centimeters long was displayed for doctors to mark their levels of understanding using a small bar (see Figure $5 \mathrm{~A}$ and $\mathrm{B}$ ). The segment did not have numerical values:

In group one, a qualitative and quantitative analysis was performed. Each orthopedic surgeon was asked to score the bar location in a way that was representative of their level of understanding of the learning objects before and after they are displayed.

After being marked, the forms were collected and the centimeters marked for each question were measured. A spreadsheet with the results of the nineteen forms was generated.
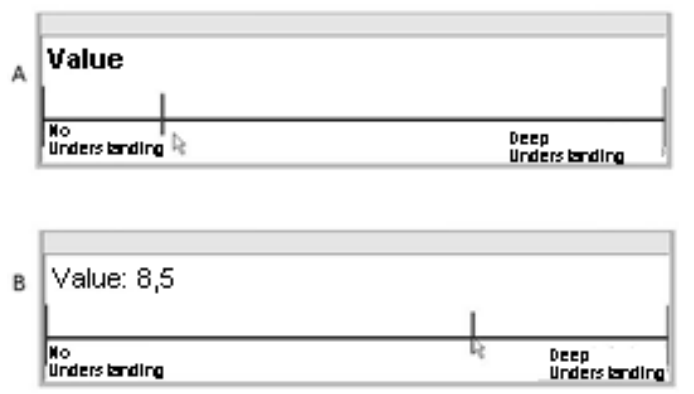

Fig. 5. (A) Line segment with a bar that can be crossed at any interval between "No Understanding" and "Deep

The quantification of perceptions was performed through the formula (1) below. This formula transformed data collected in centimeters to a scale of 10 points.

$$
Q p=\frac{v}{V} \times 10
$$

Where: Qp - quantification of perception

$\mathrm{v}$ - value set by the doctor on the line segment

$\mathrm{V}$ - the total value of the segment

Then we applied the Test $t$ Student, which is a hypothesis test used to test for differences between the mean of a random sample and the population mean, i.e., if there was a significant difference between the mean level of understanding before and after the application of 3D learning objects.

Regarding group two, the qualitative evaluation of learning objects by medical experts ranged from "poorly" to "Excellent" in the questionnaires. The quantification of perceptions was performed in the same manner described above.

Table 1 relates ranges of values with conceptual classifications, allowing the assignment of categories for the values obtained with the process of quantification of perceptions.

\section{TABLE I : DISTRIBUTION OF VALUES FOR THE QUALITATIVE CLASSIFICATION}

\begin{tabular}{cc}
\hline \hline Interval & Classification \\
\hline $0-3$ & Poorly \\
$3.1-4.9$ & Bad \\
$5-6.9$ & Regular \\
$7-8$ & Good \\
$8.1-8.9$ & Very Good \\
$9-10$ & Excellent \\
\hline \hline
\end{tabular}

Source: [27, p. 39] modified. 


\section{RESULTS}

Before discussing the final considerations of this work, it is important to note that it was not possible to assess the Scrum dynamics that were used in the work presented by Silva [32], since the team was formed only by the Product Owner, i.e. the specialist physician who guide the development of this project from the beginning; as the Scrum Master and Team were one, the author of the work, the daily meetings and the artifacts were reduced to script adaptations, and each resulting increment was a $3 \mathrm{D}$ modeling to be used by the main script.

Since the Product Owner was the specialized doctor who evaluated the 3DMLO as excellent (10 points), it can be seen that the instantiation of Scrum work presented by Silva [32] was helpful because it met the demand of the main "customer" within the perspective of software engineering.

The doctor in charge, following guidelines of the author of this study, conducted presentation and evaluation of LOs with two groups of physicians in order to evaluate the level of understanding developed through 3DMLOs.

In the evaluation process, the four LOs developed were shown to both groups - one of which was formed by interns in orthopedics and other which was formed by specialists in orthopedics. The four LOs developed for this project are presented below:

- VIDEO 01 Presentation of the Ilizarov Hexapod System (bit.ly/1iejHMZ);

- VIDEO 02 Six Degrees of Freedom (http://bit.ly/ MADtb1);

- VIDEO 03 IHS and the elongation of bones (http://bit. ly/1baQwVY);

- VIDEO 04 HIS and the correction of bone deformities (http://bit.ly/1keKxVP).

Eleven orthopedic interns of group 1 responded to the questionnaire.

The condition of normality by Shapiro-Wilks test with a significance level of 5\% (0.05) was taken into consideration on the analysis of the results obtained before and after the use of learning objects.

The results obtained before and after application of learning objects with respect to the assessment of knowledge about hexapods systems, six degrees of freedom and on IHS were expressed as mean, minimum and maximum values, and standard deviations, as shown Tables 2, 3 and 4, respectively.

TABLE II : ASSESSING THE LEVEL OF UNDERSTANDING ABOUT HEXAPOD SYSTEMS

\begin{tabular}{ccccr}
\hline \hline Variables & Average & $\begin{array}{c}\text { Minimum } \\
\text { Value }\end{array}$ & $\begin{array}{c}\text { Maximum } \\
\text { Value }\end{array}$ & $\begin{array}{c}\text { Standard } \\
\text { Deviation }\end{array}$ \\
\hline $\begin{array}{c}\text { Before } \\
\text { After } \\
\begin{array}{c}\text { Diference } \\
\text { (After }-\end{array}\end{array}$ & 1,29 & 0,71 & 2,50 & 0,57 \\
Before) & 1,68 & 0,89 & 2,86 & 0,67 \\
\hline \hline & 0,38 & 1,79 & 1,96 & 0,10 \\
\hline
\end{tabular}

TABLE III : ASSESSING THE LEVEL OF UNDERSTANDING ABOUT SIX DEGREES OF FREEDOM

\begin{tabular}{ccccc}
\hline \hline Variables & Average & $\begin{array}{c}\text { Minimum } \\
\text { Value }\end{array}$ & $\begin{array}{c}\text { Maximum } \\
\text { Value }\end{array}$ & $\begin{array}{c}\text { Standard } \\
\text { Deviation }\end{array}$ \\
\hline Before & 0,65 & 0,00 & 2,07 & 0,78 \\
$\begin{array}{c}\text { After } \\
\text { Diference } \\
\text { (After }-\end{array}$ & 2,95 & 0,79 & 4,43 & 1,17 \\
Before) & 2,31 & 0,79 & 3,64 & 0,39 \\
\hline \hline & Test $t$ de Student $(p<0,001)$
\end{tabular}

Test t Student for paired samples was performed, with significance level of $5 \%(\alpha=0.05)$, to evaluate the values obtained through orthopedic interns' responses (group one) regarding the effect of learning objects on their level of understanding [33]. The value obtained in the three cases was $p<0.009$, which demonstrated a statistically significant difference between the means and, thus, the existence of a significant increase in the level of understanding. The participants of group two, which was composed by experts in external fixators, evaluated the same learning objects.

The participants were asked to classify the learning objects. Since this group is limited, specific and difficult to access, the questionnaire was administered to eight experts only. Table 5 shows the collected data sorted by participant through the grading process and classification distribution that was explained in the chapter regarding methods

TABLE IV : ASSESSING THE LEVEL OF UNDERSTANDING ABOUT IHS

\begin{tabular}{ccccr}
\hline \hline Variables & Average & $\begin{array}{c}\text { Minimum } \\
\text { Value }\end{array}$ & $\begin{array}{c}\text { Maximum } \\
\text { Value }\end{array}$ & $\begin{array}{c}\text { Standard } \\
\text { Deviation }\end{array}$ \\
\hline Before & 1,58 & 0,93 & 1,07 & 0,54 \\
$\begin{array}{c}\text { After } \\
\text { Diference } \\
\text { (After } \\
\text { Before) }\end{array}$ & 2,14 & 1,07 & 4,07 & 0,88 \\
\hline \hline & 0,56 & 1,64 & 3,00 & 0,34 \\
\hline
\end{tabular}

TABLE V : EVALUATION OF 3DMLOS BY SPECIALISTS IN EXTERNAL FIXATORS.

\begin{tabular}{ccc}
\hline \hline Participant & Value & Classification \\
& & \\
\hline 1 & 6,50 & Good \\
2 & 5,80 & Regular \\
3 & 6,40 & Regular \\
4 & 10,00 & Excellent \\
5 & 5,60 & Regular \\
6 & 7,90 & Good \\
7 & 8,60 & Very Good \\
8 & 5,40 & Regular \\
Average & 7,03 & Good \\
\hline \hline
\end{tabular}

Although the work presented by Silva [32] has as a result the artifacts of software engineering, that are $3 \mathrm{DMLO}$ built with the support of the adaptation of Scrum, one of the weaknesses of the study was that there was no time to build other 3DMLO that met greater demand for doctors, be they specialists or residents, which is suggested for future work, as can be seen in the open question in the questionnaire was made available where the following suggestions of experts emerged: "Demonstrate in more fractures in the body", "Realization of the procedure in children", "Perform procedure in foot and ankle" and "Demonstrate how the calculations are performed."

\section{CONCLUSION}

The results of the Test $t$ Student $(p<0.009)$ showed that there was a significant increase in the level of understanding of hexapods systems, of the six degrees of freedom and of the IHS.

Similarly, researchers noticed that orthopedic interns' suggestion in reviews should also contribute for the promotion of an increase in the level of understanding as when a grade was below the doctors' average, there has always been a suggestion, made by the doctor who was 
being graded, to perform the procedure in more parts of the body. In addition, the 3DMOLs were evaluated on average by experts as "Good", with the grade 7.03 on the overall evaluation of the scale of qualification.

However, the work of adaptation of Scrum to build 3DMLOs was useful due to the fact that it was approximated to the conventional software development process, which allowed researchers to observe a likely increase in the quality of the 3DMLOs developed.

The scripts made possible to guide the development of 3DMLOs that could be easily changed and re-designed until approved for actual construction or for modeling of parts that would be contained on a final 3DMLO; this development process is similar to the traditional software development process.

Therefore, a guide was followed for the construction of objects, with meetings and documentation regarding goals for the desired 3DMLOs. However, the modeling did not always mirror the script, which required the attention of the Scrum Master after the delivery of the Sprints and Products' Backlog.

The LO which had the objective of developing the level of understanding of the IHS was implemented without much difficulty and the script was followed without many changes. This happened because it was a 2D object, in which modeling happened through video manipulation only.

On the other hand, the 3DMLOs that were designed to develop the level of understanding about the six degrees of freedom had changes to their planned schedule discussed at the weekly meeting of Scrum. This happened because the development team most often needed more time than what was estimated to complete the Sprint or the Product's Backlog.

Still in regard to 3DMLOs, it was also necessary to develop a level of understanding about the old (IEF) and new (IHS) Ilizarov methods. As in the case of the previously mentioned object, it was necessary to review the planned schedule since the $3 \mathrm{D}$ modeling took time beyond the expected in the weekly meetings.

Finally, the 3DMLO which aimed to develop the level of understanding about correcting one problem on one leg, was developed in the same way of the others. Its development faced the same difficulties regarding time. However, the team was more experienced and the deadline for phases were established based on the delays of the previous development projects, which meant that the deadline for delivery of the object was accomplished. Therefore, 3DMLO has significant influence on increasing the level of understanding in medical education.

\section{REFERENCES}

[1] P. Battistella, A. Von Wangenheim. Avaliação de Ferramentas de Autoria Gratuitas para produção de Objetos de Aprendizagem no padrão SCORM. Revista Brasileira de Informática na Educação, 19, dez. 2011. Disponível em: <http://www.br-ie.org/pub/index. php/rbie/article/view/1228/1180>. Acesso em: 29 Jan. 2014.

[2] P. E. Battistella, A. Wangenheim, C. G. Wangenheim. Evaluation of Free Authoring Tools for Producing SCORMConform Learning Objects. v. 5, n. 4. ITEE/IEEE. 2010.

[3] Bioe- Banco Internacional de Objetos Educacionais. Disponível em: $\quad<$ http://objetoseducacionais2. mec.gov.br/>. Acesso em: 17 ago. 2013.

[4] C. Cechinel, S. Sánchez-Alonso, E. García-Barriconal. Statistical profilesofhighly-ratedlearningobjectsutor.Computers\&Education, v. 57, n.1, páginas 1255-1269. ISSN: 0360-1315; DOI: 0.1016/j. compedu.2011.01.012. SciVerse ScienceDirect Journals. 2011.

[5] Ya-C. Chouw, Wei-S. Yu, Ke-J. Huang, Pei-C. Lin. Bioinspired step-climbing in a hexapod robot. Bioinspiration \& Biomimetics. DOI: 10.1088/1748-3182/7/3/036008. 2012.

[6] T. Cochrane. Developing interactive multimedia Learning Objects using QuickTime. Computers in Human Behavior, v. 23 , n. 6 , pp.2596-2640. ISSN: 0747-5632 DOI: $10.1016 /$ j. chb.2006.08.007, SciVerse, ScienceDirect Journals. 2007.

[7] T. Cochrane. Interactive QuickTime: developing and evaluating multimedia learning objects to enhance both face-to-face and distance e-learning environments. Interdisciplinary Journal of Knowledge, and Learning Objects, Annual, v.1, n.22, páginas 33. Cengage Learning, Inc.2005.

[8] G. da S. Conceição, H. F. L. Matos, M. de A. Batista; R. W. de S. Costa; R. A. Lima. A importância de Recursos Multimídia na Aprendizagem Escolar. 63 ${ }^{\mathrm{a}}$ Reunião Anual da SBPC. SBPC Jovem, Resumos de Comunicações Livres - ISSN: 2176-1221. UFG, Goiânia - GO, 2011.

[9] P. Dev. Tutorial: Imaging and Visualization in Medical Education. IEEE Computer Graphics and Applications, v. 19, n.3,páginas 21-23. 1999.

[10] M. Easley, L. Colin, S. Wellman; J. Wilson. Ankle Arthrodesis Using Ring External Fixation. Techniques in Foot and Ankle Surgery, v. 5, n. 3, páginas 150-163, 2006.

[11] D. D. G. Horovitz. Atenção aos defeitos congênitos no sistema de saúde. (Tese de Doutorado). Curso de Pós-graduação em Saúde Coletiva,UniversidadedoEstadodoRiodeJaneiro,página 149,2003.

[12] Jornal da Ciência. Natureza aplicada à vida cotidiana. Disponível em: <http://jornaldaciencia.org.br>. Acesso em: 11 nov. de 2013.

[13] A.Kybartaite, J.Nousiainen, J.Malmivuo. Learning Objects for the VirtualCampus ofBiomedical Engineering, IEEE Multidisciplinary Engineering Education Magazine (MEEM), - submitted, 2010.

[14] E. Lima Júnior, J. Knopfhoz, C. M. Menini. Estresse Durante Cursos de Suporte de Avançado de Vida em Cardiologia. É importante no Aprendizado de Habilidades? Arquivo Brasileiro de Cardiologia, v. 79, n. 6, páginas $585-588,2002$.

[15] Litos, Precision Hexapod - The Optimal Extension for all Ilizarov external fixation systems. 2006. Disponível em: $\quad<\mathrm{http}: / /$ litos.com/upload/files/Produkt-PDFs/litos Praezisions-Hexapod.pdf $>$. Acesso em: 10 jul. 2013.

[16] V. Mckusick. The Gordon Wilson Lecture: The Clinical Legacy Of Jonathan Hutchinson (1828-1913): Syndromology and Dysmorphology Meet Genomics. Trans Am Clin Climatol Assoc, v. 116, páginas 15-38, 2005.

[17] C. B. Mello. Controle de Trajetória de uma Plataforma de Stewart para Simulação de Transferência de Carga Fora de Porto. UniversidadeFederaldoRiode Janeiro, Riode Janeiro,Abrilde2011.

[18] J.P.Merlet,ParallelRobots-2ed.v.128.Netherlands, Springer.2006.

[19] J. M. Moran, M. T. Masetto, M. A. Behrens. Novas tecnologias e mediação pedagógica. Campinas, SP: Papirus, 2000.

[20] J. Najjar, E. Duval. Actual Use of Learning Objects and Metadata An Empirical Analysis. Computer Science Department, K.U.Leuven, B-3001 Leuven, Belgium, IEEE, 2003.

[21] S. Nangia. MERLOT in the classroom: enhancing foreign language instruction through online learning objects. Michigan Academician, Spring, v. 40, n. 1, página 105, ISSN: 0026-2005, Cengage Learning, Inc. 2010.

[22] V. B. Penchaszadeh. Genética y salud pública. Boletín de la Oficina sanitaria panamericana. v. 115, n.1, páginas 1-11. 1993.

[23] Z. Pizlo, T. Sawada, Y. Li, W. G. Kropatsch, R. M. Steinman. New approach to the perception of 3D shape based on veridicality, complexity, symmetry and volume. ISSN: 0042-6989; DOI: 10.1016/j. visres.2009.09.024. SciVerse ScienceDirect Journals. 2009.

[24] Projeto Homem Virtual. Website do Projeto Homem Virtual. Disponível em: $<$ http://www. projetohomemvirtual.com.br/>. Acesso em: 17 ago. 2013.

[25] J. O. R. Neto, C. S. Cunha, C. S. Cunha, A. N. Rodrigues, M. Tavares. Aprendizagem baseada em problemas: o mito e realidade. Cadernos UniFOA. Edição n ${ }^{\circ} 16$ - Agosto/2011.

[26] A. P. Ramos, M. N. D. Oliveira, J. P. Cardoso. Revalência de 
Malformações Congênitas e Recém-Nascidos em Hospital da Rede Pública. Revista Saúde.Com, v. 4, n. 1, pp. 27-42. 2008.

[27] B. C. Ribeiro. Identificação de Dismorfologias utilizando Objetos de Aprendizagem. Pontifícia Universidade Católica do Paraná, Pós-Graduação em Ciências da Saúde. Curitiba, 2009.

[28] R. de Santiago, A. L. A. Raabe. Architecture for Learning Objects Sharing among Learning Institutions-LOP2P. vol. 3 no. 2, pp. 91-95 - UNIVALI - Unversidade do Vale do Itaja. Disponível em: <http://doi.ieeecomputersociety. org/10.1109/TLT.2010.9>. $\quad$ Abril/Junho 2010.

[29] N. F. P. Santos. Modelização de Um Sistema de Simulação de Uma Aeronave Aplicado a Uma Plataforma Electromecânica de Goug-Stewart. Dissertação de Mestrado, Instituto Superior de Engenharia de Lisboa, Universidade de Lisboa. 2010.

[30] J. M. C. da Silva, R. M. Vicari. Evaluating a Brazilian Metadata to Learning Objects to Web, Mobile and Digital Television Platforms. Federal University of Rio Grande do Sul - Postal Code 15064, Porto Alegre/RS, 91501-970, Brazil, IEEE. 2010.

[31] R. W. A. D. Silva, Educação à Distância em Ambientes de Aprendizagem Matemática Auxiliada pela Realidade Virtual. (Dissertação de Mestrado). Programa de PósGraduação em Engenharia de Produção, Universidade Federal de Santa Catarina, Florianópolis, 2001.

[32] M. H. L.F. da Silva. Desenvolvimento de objetos de aprendizagem multimídia com auxílio do Scrum: uma experiência no contexto da ortopedia e das plataformas de Stewart. (Dissertação de Mestrado). Programa de Pós-Graduação em Informática Aplicada, Universidade Federal Rural de Pernambuco, Pernambuco, 2013.

[33] R. B. V. Silva, D. F. Ferreira. Alternativas para o teste $\mathrm{t}$ com variâncias heterogêneas avaliadas por meio de simulação. Ciênc. agrotec. v. 27 n.1 Lavras Jan/Fev. 2003.

[34] R. S. Stoughton, T. Arai. A modified Stewart platform manipulator with improved dexterity. Robotics and Automation, IEEE Transactions. DOI: 10.1109/70.238280, Page(s): 166. IEEE JOURNALS \& MAGAZINES. 1993.

[35] F. P.Torgal, S. Jalali. Materiais Biomiméticos: Materiais de construção inspirado na natureza. C-TAC - Artigos em Revistas Nacionais. Mar 2011.

[36] D. A. Wiley. Connecting learning objects to instructional design theory: A definition, a metaphor, and a taxonomy. 2012. Digital Learning Environments Research Group. Acesso em: 25 ago 2012. Disponível em: < http://wesrac.usc.edu/wired/bldg-7_file/wiley.pdf

[37] R. J. Windle, H. Wharrad, D. Mccormick, H. Laverty, M. Taylor. Sharing and Reuse in OER: Experiences Gained from Open Reusable Learning Objects in Health. Journal of Interactive Media in Education,ISSN: 1365-893X.ERIC(U.S.Dept.ofEducation). 2010.

[38] N. Y. Yen, T. K. Shih, L. R. Chao, Q. Jin. Ranking Metrics and Search Guidance for Learning Object Repository, v. 3, n. 3. pp. 250-264. Disponível em: <http://doi.ieeecomputersociety. org/10.1109/TLT.2010.15>, IEEE, Julho/Setembro 2010.

[39] A. T. Reis, R. da S. Santos, T. A. R. Mendes. Prevalência de Malformações Congênitas no Município do Rio de Janeiro, Brasil, Entre 2000 e 2006. Revista de Enfermagem UERJ, Rio de Janeiro, 2011.

[40] G. Olimpo, R. M. Bottino, J. Earp, M. Otti, F. Pozzi, M. Tavella. Pedagogical plans as communication oriented objects. Computers \& Education, v. 55,n. 2, pp.476-488. ISSN: 0360-1315; DOI: 0.1016/j. compedu.2010.02.011. SciVerse ScienceDirect Journals. 2010.

[41] M. H. L. F. Silva, A. J. S. Rodrigues, E. B. Carvalho, J. C. Silva Neto, G. B. Lins, R. D’emery, J. F. Silva Júnior, M. M. Teixeira. Recognition of bone deformities in radiographs to identify strategic points of bone section in the use of a Ilizarov hexapod system. In: 2017 12th Iberian Conference on Information Systems and Technologies (CISTI), 2017, Lisbon, Portugal: IEEE, 2017. p. 1-6. DOI: 10.23919/CISTI.2017.7975949

[42] T. Marcelo Mendonça, F. Tiago Alessandro Espínola. The communicationmodelofvirtualuniverse.Munich:GrinVerlag,2014. 